\title{
A FORMAC̣̃̃O PEDAGÓGICA NO CURSO DE LICENCIATURA EM FÍSICA: ARTICULAÇ̃̃O ENTRE OS CAMPOS DO CONHECIMENTO
}

\author{
JOANA PAULIN ROMANOWSKI ${ }^{1 *}$ \\ https://orcid.org/0000-0001-7043-5534 \\ PRISCILA JULIANA DA SILVA ${ }^{2 *}$ \\ https://orcid.org/0000-0002-1672-6143
}

RESUMO: Este artigo resulta de uma pesquisa qualitativa realizada em um curso de Licenciatura em Física ofertado em um Instituto Federal de Educação, Ciência e Tecnologia, localizado em Santa Catarina. A investigação buscou identificar e analisar as prioridades apontadas pelo Projeto Pedagógico de Curso para a formação de professores e descrever as práticas pedagógicas dos professores que atuam nesse curso. Os dados foram coletados por meio de análise documental do Projeto Pedagógico de Curso e entrevistas semiestruturadas com professores. A análise dos dados seguiu a análise de conteúdo proposta por Bardin (1999), que tem três passos: pré-análise, descrição analítica e interpretação referencial. As conclusões apontam que a Licenciatura em Física, em sua organização curricular, tem como prioridades a articulação de conhecimentos específicos e pedagógicos, a pesquisa como princípio educativo, a interdisciplinaridade e a relação da instituição com a educação básica.

Palavras-chave: Formação de Professores; Licenciatura em Física; Formação Pedagógica.

\section{LA FORMACIÓN PEDAGÓGICA EN EL CURSO DE LICENCIATURA EN LA FÍSICA: ARTICULACIÓN ENTRE LOS CAMPOS DEL CONOCIMIENTO}

RESUMEN: Este artículo resulta de una investigación cualitativa realizada en una graduación en Licenciatura en la Física ofertado en un Instituto Federal de Educación, Ciencia y Tecnología, en Santa Catarina, Brasil. La investigación buscó identificar y analizar las prioridades apuntadas por el Proyecto Pedagógico de Curso para la formación de profesores y describir las prácticas pedagógicas de los profesores que actúan en este curso. Los datos fueron recogidos por medio del análisis documental del Proyecto Pedagógico de Curso y entrevistas semiestructuradas

*Doutorado em Educação pela
Universidade de São Paulo (2002).
Mestre em Educação pela
Universidade Federal do Paraná (1985).
Atualmente é professora titular
da Pontifícia Universidade Católica
do Paraná - PPGE e colaboradora
no Centro Universitário UNINTER.
E-mail: < joana.romanowski@gmail.com >.
** Doutoranda em Educação
na Universidade Federal do Paraná.
Mestre em Educação pela
Pontifícia Universidade Católica
do Paraná (2017). Pedagoga no
Instituto Federal de Santa Catarina.
E-mail: < priscila.silva@ifsc.edu.br $>$.

\footnotetext{
${ }^{1}$ Pontifícia Universidade Católica do Paraná, Curitiba, PR - Brasil.

${ }^{2}$ Instituto Federal de Santa Catarina, Florianópolis, SC - Brasil.
} 
con profesores. El análisis de los datos siguió el análisis de contenido propuesta por Bardim (1999), que tiene tres pasos: preanálisis, descripción analítica e interpretación curricular, tiene como prioridades la articulación de conocimientos específicos y pedagógicos, la investigación como principio educativo, la interdisciplinariedad y la relación de la institución con la Educación Básica.

Palabras clave: Formación de profesores; Licenciatura en la Física; Formación Pedagógica.

\section{TEACHING FORMATION IN PHYSIC'S TEACHING COURSE: ARTICULATION BETWEEN KNOWLEDGE FIELDS}

ABSTRACT: This article results from a qualitative research carried out in a graduation course in Physics Teaching offered at an Federal Institute of Education, Science and Technology located in Santa Catarina-Brazil. The research sought to identify and analyze the priorities pointed out by the Pedagogical Course Project for the teacher education and to describe the pedagogical practices of the teachers who work in this course. Data was collected through documentary analysis of the Pedagogical Course Project and semi-structured interviews with teachers. The analysis of the data followed the Content Analysis proposed by Bardin (1999) that has three steps: Pre-analysis, Analytical Description and Referential Interpretation. The conclusions indicate that the curricular organization of this Physics Teaching course presents, as priorities, the articulation of specific and pedagogical knowledge, research as an educational principle, interdisciplinarity and the relationship of the institution with Basic Education.

Keywords: Teacher Education; Undergraduate in Physics; Education. 


\section{INTRODUÇÃO}

Diversas pesquisas realizadas no campo da formação de professores apontam, até recentemente, que as licenciaturas, no Brasil, eram organizadas em um modelo conhecido como 3+1, ou seja, três anos de disciplinas específicas e um ano de disciplinas pedagógicas. Tal dualidade é evidenciada por inúmeros autores, entre eles, Saviani (2009), Gatti (2010), Lüdke e Cruz (2005) e Marcelo (1999). Esse modelo, também chamado racionalidade técnica, privilegia o conhecimento específico, em detrimento do conhecimento pedagógico. Tal desvalorização do conhecimento pedagógico e dualidade entre conhecimentos são mostradas por Saviani (2009) como resultado histórico da constituição dos cursos de licenciatura no Brasil.

A racionalidade técnica foi introduzida no país no período de 1939 a 1971. Nessa ocasião, os institutos de educação, que ofereciam formação de professores, foram elevados ao nível universitário pelo Decreto n ${ }^{\circ}$ 1.190/1939 (BRASIL, 1939), o qual delineou a estrutura dos cursos de graduação em nível universitário. Portanto, a partir dessa normativa foi iniciado um processo pelo qual os cursos de formação de professores tornaram-se segmentados entre o conhecimento específico e o conhecimento pedagógico, pois, primeiramente, o licenciado cursava disciplinas da área específica de sua formação e, no fim do curso, realizava disciplinas pedagógicas e práticas de ensino. Dessa forma, as licenciaturas brasileiras se estabeleceram, historicamente, de modo compartimentado, pois uma "sólida" formação teórica era seguida de aplicação na prática docente.

Atualmente, as políticas educacionais têm impulsionado modificações nesse modelo, incentivando as práticas pedagógicas pelo estágio obrigatório e pelas práticas como componente curricular (BRASIL, 2015). Além de fomentar mudanças nas estruturas curriculares, têm incentivado a criação de cursos e vagas de licenciaturas em todo o país, em especial, na rede federal de educação profissional e tecnológica, com o objetivo de suprir a carência histórica de professores das ciências exatas. Tais políticas estão presentes na lei de criação dos institutos federais de educação, ciência e tecnologia, que estabelecem que $20 \%$ de sua oferta de vagas devem ser destinadas à formação inicial e continuada de professores (BRASIL, 2008).

A situação das licenciaturas em números é mostrada por Romanowski (2002), que discute o impacto da expansão demográfica do país e da universalização da educação básica no número de matrículas no ensino superior. Segundo a autora, apesar do aumento de matrículas no ensino superior, quando se considera o número de matrículas nas licenciaturas, têm-se números maiores nas áreas referentes às ciências humanas, enquanto números bem menores são encontrados nas ciências exatas (ROMANOWSKI, 2002). Enfatiza, ainda, o elevado índice de evasão e baixo índice de conclusão nas licenciaturas nas áreas de ciências, química, física e matemática. No caso específico das Licenciaturas em Física, verifica-se um histórico de poucos cursos e vagas e alta demanda por esses profissionais, devido à crescente ampliação da escolarização no país. Além disso, os índices de evasão são alarmantes e, apesar do aumento da oferta de cursos e vagas, ocorre uma porcentagem alta de vagas ociosas. A esse respeito, os dados apresentados por Gatti e Barreto (2009), reforçam a necessidade de formação de professores 
de física. As autoras destacam que dos professores atuantes no ensino médio, nas disciplinas de física, somente $9 \%$ têm formação na área específica.

Ao discutir o aumento da oferta de cursos de Licenciatura em Física na rede de educação profissional e tecnológica, Higa e Garcia (2012) avaliam que essas instituições podem estabelecer novas concepções e estruturas curriculares, desenvolvendo formas inéditas de pensar e fazer a formação de professores, pois não têm um histórico tradicional com a formação de professores.

Cabe salientar que os Institutos Federais de Educação, Ciência e Tecnologia (IF) iniciaram a oferta de cursos de licenciatura a partir de 2008, por meio da obrigatoriedade de $20 \%$ de suas vagas serem destinadas para cursos de formação inicial e continuada de professores. Essa obrigatoriedade foi instituída pela Lei 11.892 (BRASIL, 2008). Essa lei define o caráter diverso dos IF que inclui a oferta de cursos técnicos de nível médio, integrado e concomitante ao Ensino Médio, cursos na modalidade da Educação de Jovens e Adultos, cursos superiores tecnológicos e bacharelado, e pós-graduação lato e stricto senso. Essa diversidade de cursos impacta na atuação dos professores. Com efeito, os docentes pertencem à carreira do ensino básico, técnico e tecnológico, em que a atuação profissional do professor desses Institutos transita por diversas faixas etárias de alunos, modalidades e níveis de ensino, portanto não está restrita ao Ensino Superior. Como é uma instituição recém-criada, somam-se os desafios de construir e consolidar programas de pesquisa e de extensão.

Diante desse cenário de novas possibilidades para a formação de professores nos Institutos Federais, esta pesquisa destaca como objeto a formação pedagógica na formação de professores, compreendida como a relação e articulação entre os campos de conhecimentos específicos e pedagógicos. A pesquisa foi realizada em um curso de Licenciatura em Física em um Instituto Federal de Educação, Ciência e Tecnologia do estado de Santa Catarina. Para problematizar o objeto de pesquisa algumas questões norteadoras foram fundamentais: Quais as prioridades da formação de professores no curso de Licenciatura em Física? Como se expressa a relação entre os conhecimentos específicos e pedagógicos nos documentos institucionais da Licenciatura em Física? Que formação pedagógica é expressa pelos docentes da Licenciatura em Física? A partir dessas questões, este artigo examina a organização curricular e a formação pedagógica no curso de Licenciatura em Física e define por objetivos: identificar e analisar as prioridades apontadas pelo Projeto Pedagógico de Curso para a formação pedagógica dos professores de física e descrever as práticas pedagógicas dos professores que atuam nesse curso.

\section{FUNDAMENTOS E PROCEDIMENTOS METODOLÓGICOS}

A abordagem metodológica desta pesquisa é qualitativa, pois tem o ambiente natural como sua fonte direta de dados e o pesquisador como seu principal instrumento no processo de pesquisa (LÜDKE; ANDRÉ, 1986). Os dados coletados foram predominantemente descritivos e o significado que as pessoas dão aos elementos de investigação foi foco de atenção especial. Por isso, a análise dos dados seguiu um processo indutivo, pois, ao longo dele, foram construídas as categorias da pesquisa, de modo não linear, tendo os objetivos e os referenciais teóricos dialogado com os dados empíricos. 
O espaço de realização desta pesquisa foi um curso de Licenciatura em Física ofertado em um Instituto Federal de Educação, Ciência e Tecnologia, localizado em Santa Catarina. Esse curso tem 15 professores e atende a aproximadamente 90 estudantes. A primeira turma de licenciatura ofertada por essa instituição iniciou as aulas em 2009, em um curso de Licenciatura em Ciências da Natureza com Habilitação em Física. Ao longo do tempo, problemas na dupla diplomação proposta (Licenciatura em Ciências e Licenciatura em Física) fizeram a instituição rever sua proposta pedagógica e iniciar, em 2014, a primeira oferta do curso de Licenciatura em Física com uma única habilitação. Esse curso tem previsão de formar sua primeira turma em 2018.

Para investigar o curso, foram definidos para a coleta de dados três instrumentos: a análise documental do Projeto Pedagógico de Curso e do Regulamento da Prática Pedagógica como Componente Curricular, observações participantes das reuniões do Núcleo Docente Estruturante e entrevistas semiestruturadas com professores que atuam no curso. Neste artigo, são explorados os dados e categorias da análise documental do Projeto Pedagógico de Curso e de entrevistas semiestruturas realizadas com três professores, para discutir duas categorias da pesquisa: as prioridades para a formação de professores proposta no Projeto Pedagógico de Curso e as práticas pedagógicas dos professores da Licenciatura em Física.

Foram entrevistados três professores do curso que participam do Núcleo Docente Estruturante. Esse núcleo tem caráter consultivo nos cursos de graduação e é responsável pelo acompanhamento do projeto pedagógico de curso, avaliando e propondo estratégias para sua consolidação. Para escolha dos professores entrevistados e a construção do roteiro de entrevista, foram utilizados dados da fase exploratória da pesquisa, que aconteceu por meio de observações participantes de duas reuniões do Núcleo Docente Estruturante, com duração de aproximadamente duas horas cada. A seguir apresentamos um breve perfil dos professores entrevistados.

O professor A possui formação em Física, no momento da realização da pesquisa possuía um ano de experiência docente na Educação Básica e sete anos como professor em cursos de engenharia em uma instituição privada e um ano de experiência docente no já referido Instituto, na Licenciatura em Física. A opção de entrevistar esse professor é devida a sua formação específica em física e por estar envolvido diretamente na reformulação do curso.

O professor B é formado em Biologia e atua nas disciplinas interdisciplinares do curso de licenciatura investigado. A escolha desse professor foi motivada por sua pouca participação nas discussões nas reuniões do NDE. Esse professor tem sete anos de experiência na docência do Ensino Superior em instituições privadas e atua como docente no Instituto Federal de Educação, Ciência e Tecnologia na Licenciatura em Física e nos cursos técnicos de nível médio, desde a criação desse instituto.

O professor $C$ possui formação em Pedagogia e atua nas disciplinas pedagógicas do curso de Licenciatura em Física. Nas reuniões observadas, esse professor exemplificou a prática pedagógica como componente curricular nas disciplinas em que atua. A prática relatada tem relação com a Educação Básica e ao vincular os conhecimentos teóricos à realidade escolar utilizando como metodologia a realização de observações. Esse professor tem cinco anos de experiência como docente na Licenciatura em Física, tendo acompanhado o processo de extinção 
do curso de Licenciatura em Ciências da Natureza com habilitação em Física, anteriormente ofertado pela instituição pesquisada, e participado da elaboração do projeto pedagógico de curso da Licenciatura em Física. Sua experiência profissional anterior foi como orientador educacional e coordenador pedagógico em escolas da Educação Básica públicas e privadas.

Para Triviños (1987), a análise documental é um estudo descritivo que possibilita ao investigador grande quantidade de informações provindas de leis, regulamentos e documentos oficiais. Nessa técnica de coleta de dados, são escolhidos documentos significativos para o problema de pesquisa. No caso deste estudo, foi considerado o Projeto Pedagógico de Curso o documento mais significativo para a compreensão das prioridades para a formação de professores defendida pelo corpo docente.

Quanto à entrevista, segundo Flick (2009), a semiestruturada pode ter três tipos de questão: (i) abertas, porque podem ser respondidas pelo entrevistado utilizando seu conhecimento; (ii) direcionadas pela teoria ou pelas hipóteses que o pesquisador já elaborou; (iii) confrontativas, ou seja, colocar em questão as teorias e as questões apresentadas pelo entrevistado. Nesta pesquisa, as questões da entrevista semiestruturada foram abertas e direcionadas, tendo sido respondidas com a vivência e conhecimentos dos entrevistados e direcionadas por observações participantes das reuniões do Núcleo Docente Estruturante.

$\mathrm{Na}$ análise de dados, foram seguidos os passos para a análise de conteúdo sugeridos por Triviños (1987), Bardin (1999) e Lüdke e André (1986). No primeiro passo, chamado pré-análise, foi feita uma primeira leitura dos documentos para visualizar seu conjunto e extrair particularidades para uma primeira categorização e classificação. O quadro 1 exemplifica as categorias de análise e suas unidades.

Quadro 1. Categorias e Unidades de Análise

\begin{tabular}{|c|l|}
\hline CATEGORIAS & \multicolumn{1}{c|}{ UNIDADES DE ANÁLISE } \\
\hline $\begin{array}{c}\text { Prioridades para } \\
\text { a formação de } \\
\text { professores }\end{array}$ & $\begin{array}{l}\text { Relação da instituição com a Educação Básica } \\
\text { Pesquisa como princípio educativo } \\
\text { Núcleos de conhecimento e suas articulações } \\
\text { Diferenças entre os cursos de Bacharelado e Licenciatura }\end{array}$ \\
\hline \multirow{2}{*}{$\begin{array}{c}\text { As práticas dos } \\
\text { professores }\end{array}$} & $\begin{array}{l}\text { Interdisciplinaridade; } \\
\text { Prática como Componente Curricular - Práticas } \\
\text { Núcleo Problematizador } \\
\text { Pesquisa como princípio educativo }\end{array}$ \\
\hline
\end{tabular}

Na leitura flutuante todos os documentos, já organizados e com as gravações das observações participantes e as entrevistas semiestruturadas transcritas, foram lidos e receberam as primeiras marcações livres em pontos que expressavam as concepções da teoria e prática e de outros pontos ligados aos objetivos de pesquisa. Em uma segunda leitura, foi iniciado um processo de agrupamentos de partes dos documentos utilizando como critérios similaridades. Nessa fase cada documento foi tratado de forma individual e recebeu agrupamento individual. 
$\mathrm{Na}$ descrição de elementos de análise os referenciais teóricos e a legislação constituíram apontamentos de conceitos e preceitos teóricos que poderiam fundamentar os elementos agrupados na primeira parte da leitura flutuante e se iniciou um diálogo das teorias com os elementos de cada documento. Todos os documentos foram lidos novamente e outros elementos com potencialidades para a formação de professores foram marcados. Por fim na inter-relação de elementos de análise foram relacionados todos os agrupamentos buscando encontrar os pontos de encontro e contradição. Nesses momentos as ausências foram percebidas e as frequências evidenciadas. Assim, com base nos objetivos da pesquisa foram definidos duas categorias, prioridades para a formação de professores e as práticas dos professores. Para esse artigo foram destacados, especialmente, pontos das categorias de análise que estivessem direcionados ao foco abordado.

\section{CURRÍCULO E FORMAÇÃO DE PROFESSORES}

A formação de professores no Brasil tem apresentado diversos desafios e avanços. Novas diretrizes para a formação docente têm estimulado, desde 2002, a quebra das barreiras dicotômicas das estruturas curriculares, com o objetivo de realizar a articulação entre teoria e prática, conhecimento específico e pedagógico e instituição de ensino e educação básica.

Nas atuais Diretrizes Nacionais para a Formação Inicial em Nível Superior e a Formação Continuada (Resolução CNE/CP n 02, de 01 de julho de 2015) a prática e a experiência são elementos presentes para os processos formativos, e inclusive teve o tempo ampliado para a organização dos projetos pedagógicos de curso, como por exemplo, às 400 horas de estágio e às 400 horas de prática como componentes curriculares, ambas obrigatórias de acordo com a referida resolução. Para Dourado (2015, p. 300), essa ampliação do tempo se atrela à centralidade do trabalho como princípio educativo, portanto favorece a "práxis como expressão da articulação entre teoria e prática e à exigência de que se leve em conta a realidade dos ambientes das instituições educativas da educação básica e da profissão".

Segundo Pimenta e Lima (2011) é importante para a formação de professores que os estágios e práticas estejam presentes ao longo de todo o curso de licenciatura para que o docente tenha contato durante toda a sua formação com a atuação profissional. Dessa forma, a prática se torna um campo de conhecimento integrante de todo projeto curricular.

Neste contexto de transição em que a realidade da Educação Básica e a produção científica do campo da formação de professores estão em debate o desafio é de estabelecer a articulação entre teoria e prática, conhecimento específico e pedagógico e instituição de educação superior e educação básica. Dessa forma, é importante a compreensão das formas de organização curricular.

A organização curricular das licenciaturas é discutida por Marcelo (1999), tendo como critério a organização do conhecimento. O primeiro modelo analisado pelo autor é chamado segmentado e pode se desdobrar em duas formas: concorrente e consecutivo. O currículo concorrente desenvolve ao mesmo tempo os conteúdos da formação específica e da formação pedagógica, mas de modo separado, ou seja, sem estabelecer relações. Por sua vez, o currículo consecutivo apresenta primeiro 
o conhecimento específico e depois o conhecimento pedagógico e também não estabelece relações entre eles. Apesar de terem ordens diferentes na organização do conhecimento, ambos têm características disciplinares; os conteúdos específicos e pedagógicos são "[...] pouco ligados entre si, de tal modo que se espera que sejam os estudantes a realizar a integração dos mesmos" (MARCELO, 1999, p. 78).

O segundo modelo apresentado por Marcelo (1999, p. 77) é o currículo integrado, que se caracteriza pela "[...] ausência de territórios disciplinares, existindo uma profunda interconexão conceptual e estrutural entre os diferentes cursos para alcançar algumas metas interdisciplinares". Para o autor, esse currículo exige um elevado nível de compromisso dos professores e sua limitação reside na necessidade de maior tempo para a preparação das aulas e na grande dificuldade dos docentes em desenvolvê-lo.

O terceiro modelo de currículo é o colaborativo. Segundo Marcelo (1999), ele não estabelece relações profundas de conexão interdisciplinar, como o integrado, mas não é totalmente dividido, como o segmentado. Dessa forma, mantém a estrutura disciplinar, mas tem momentos e disciplinas em que se estabelecem inter-relações entre os conhecimentos, por meio de temas concretos, em que o professor sintetiza dados provenientes de outras áreas do conhecimento. Os três modelos curriculares apresentam níveis de relação entre os conhecimentos, indo da separação à integração total.

Santomé (1998), por sua vez, apresenta dois modelos curriculares, disciplinar e integrado, diferenciando-os dos conceitos de disciplina e interdisciplinaridade. Para o autor, disciplina

[...] é uma maneira de organizar e delimitar um território de trabalho, de concentrar a pesquisa e as experiências dentro de um determinado campo de visão. Daí que a disciplina nos oferece uma imagem particular da realidade, isto é, daquela parte que entra no ângulo de seu objetivo (SANTOMÉ, 1998, p. 55).

Desse modo, o currículo disciplinar é aquele que oferece experiências compartimentadas da realidade, caracterizando-se por ser um conjunto de disciplinas justapostas em que o domínio de cada conteúdo constitui o requisito para a mobilidade escolar.

Já a interdisciplinaridade, para Santomé (1998), é fundamentalmente um processo e uma filosofia de trabalho que entra em ação na hora de enfrentar os problemas da realidade social e se divide em cinco modalidades: (i) multidisciplinaridade: nível mais baixo de comunicação entre as disciplinas, pois não se estabelece claramente a interligação entre elas; (ii) pluridisciplinaridade: justaposição de disciplinas próximas; (iii) disciplinaridade cruzada: uma das disciplinas impõe à outra suas teorias e metodologias; (iv) interdisciplinaridade: intercomunicação e interação entre disciplinas; (v) transdisciplinaridade: sem limites disciplinares, o conhecimento é visto como um todo.

O currículo integrado, tanto para Marcelo (1999) quanto para Santomé (1998), tem como objetivo a inter-relação dos conhecimentos, tendo como principal base a experiência e a ação no processo de ensino e aprendizagem. Nele, não se utiliza o termo "disciplina", mas, sim, unidade curricular. Isso porque, enquanto 
nas disciplinas são desenvolvidos conteúdos que não têm nenhuma relação com outras áreas do conhecimento, nas unidades curriculares se estabelecem as modalidades da interdisciplinaridade e, consequentemente, o foco é a relação entre os conhecimentos. Assim, para estes autores a interdisciplinaridade na formação de professores pode ser realizada como estratégias incorporadas nos Projetos Pedagógicos de Curso e nas práticas pedagógicas para desenvolver unidades curriculares em que os conhecimentos são articulados.

Especialmente, em um currículo que tem como objetivo estabelecer relações para a formação docente, o vínculo da instituição formadora com a educação básica é um princípio fundamental que articula a teoria e prática, possibilitando uma formação contextualizada da realidade social em que o futuro professor irá atuar. Marcelo (1999) defende que é necessário existir um trabalho colaborativo entre a instituição formadora de professores e a escola de educação básica, pois esta pode ser vista como um espaço de formação inicial e continuada. Nesse sentido, as práticas de ensino são fundamentais para que o licenciando tenha proximidade com seu campo profissional ao longo de toda a sua formação. Os estágios, tradicionalmente, têm esse objetivo e, mais atualmente, as práticas, como componentes curriculares, têm se organizado para também atendê-lo, uma vez que, durante elas, “[...] os alunos aprendem a compreender a escola como um organismo em desenvolvimento" (MARCELO, 1999, p. 103). Essa importante relação entre instituição formadora e educação básica também é destacada por Lüdke e Cruz (2005), que reforçam as possibilidades de a pesquisa ser o meio de estabelecer essa ligação, quando a realidade da educação básica se torna objeto de pesquisa. Portanto, a concepção de pesquisa como princípio educativo na formação de professores favorece a articulação de conhecimentos, estabelecendo a aproximação com a Educação Básica e coloca o licenciando como produtor de conhecimentos.

Para refletir sobre a organização curricular das licenciaturas, cabe destacar os conhecimentos fundamentais para a formação docente. Entre os conhecimentos próprios da profissão docente, está o conhecimento pedagógico do conteúdo, que, segundo Shulman (2005), se constrói com a experiência e articula os diversos conhecimentos do professor, entre eles, os específicos e pedagógicos. Dessa forma, a organização curricular das licenciaturas, para desenvolver a formação pedagógica, precisa ter estratégias de articulação entre os conhecimentos e proporcionar espaço para experiências práticas.

No Brasil, a didática passou por diversas fases, enfocando dimensões diferentes ao longo do tempo, em que a relação conteúdo-forma se organiza de modos distintos permitindo sua ressignificação teórica e prática. Suas mudanças desde 1970 influenciaram as políticas públicas e as pesquisas na educação, impactando as concepções de ensino e aprendizagem. Candau (1999) demonstra essas alterações ao defender três dimensões como fundamentais para a didática: a dimensão técnica, a dimensão política e a dimensão humana. A articulação delas é chamada pela autora de didática fundamental.

$\mathrm{Na}$ trajetória histórica da didática, segundo Candau (1999), ocorreu a priorização de uma das dimensões, em detrimento das outras. Até aproximadamente 1980 , por exemplo, houve a predominância da dimensão técnica e um silenciamento 
da dimensão política, com a ênfase dada no Brasil à pedagogia tecnicista. Candau (1999) disserta que essa fase teve um caráter idealista, porque a análise da prática das escolas de educação básica não era objeto de reflexão e a didática era uma estratégia para alcançar produtos, desenvolvida como uma didática ideal. A partir de 1980, as críticas a essa didática acentuaram-se, tendo como principal argumento a falsa neutralidade da pedagogia tecnicista. Nesse movimento de crítica, a ênfase passou para a dimensão política e o questionamento sobre o papel da educação na sociedade. Nas pesquisas na área da educação, buscava-se a aproximação com as escolas e os professores, reformulando as metodologias de pesquisa e, aos poucos, tornando a pesquisa qualitativa predominante no campo.

Essas alterações da didática influenciaram sua organização para uma visão global do processo de ensino e aprendizagem, visando a uma prática pedagógica contextualizada. Ao longo da sua reestruturação, Candau (1999) salienta o surgimento de um novo elemento: o conteúdo, a estrutura e a organização interna de cada área do conhecimento específico. Dessa forma, a didática passou a ser estruturada se articulando com a área específica de formação do licenciado, o que implicou novas formas de pensar o fazer pedagógico e possíveis mudanças na estrutura curricular das licenciaturas. Assim, a didática assumiu nova epistemologia e formas, gerando nas licenciaturas disciplinas que articulam os conhecimentos específicos da didática com os conhecimentos específicos de cada licenciatura.

Essa concepção de didática e, consequentemente, de formação pedagógica coloca-se de forma contraditória para a formação de professores de física quando se toma por referência a legislação que regulamenta a construção de seus projetos pedagógicos de curso. Segundo Araújo e Vianna (2010), o Parecer CNE no 1.304, de 4 de dezembro de 2001 (BRASIL, 2001) estabelece que os projetos pedagógicos de curso na área de física estejam organizados compostos por núcleos: comum, sequencial e complementar. Os autores chamam esse esquema de $2+2$, pois há um núcleo comum a qualquer habilitação na formação em física, diferenciando-se apenas os módulos sequenciais e complementares. No caso da Licenciatura em Física, o curso deve ter um núcleo inicial comum à formação do bacharel e um módulo sequencial de licenciatura.

Camargo (2007) discute as diretrizes para a formação de professores de física no contexto da reformulação curricular de um curso de Licenciatura em Física de uma universidade pública, demonstrando que o parecer citado (BRASIL, 2001), que estabelece um modelo $2+2$, propõe a formação de um físico educador. Segundo o autor, nessa proposta, "[...] todos ingressariam em um curso de Física e teriam dois anos de Física básica; depois, cada um escolheria sua opção, ou outras terminalidades, dentre elas, a de físico-educador" (CAMARGO, 2007, p. 238). Ainda, aponta que a Resolução CNE no 2, de 19 de fevereiro de 2002 (BRASIL, 2002), que estabelece as diretrizes para os cursos de formação de professores para a educação básica, propõe a formação de um educador em física. Camargo (2007, p. 238) argumenta que essa legislação propõe que, ao ingressar em uma Licenciatura em Física, se exige "[...] um exercício constante para o licenciando entender que, a partir desse momento não será mais aluno; vai passar por um processo que culminará em torná-lo um professor". Reforçando a formação de um educador em física, a Resolução no 2/2015 (BRASIL, 2015) define diretrizes para a formação inicial e continuada de professores, independentemente da habilitação específica, buscando dar organicidade a ela. 
A formação pedagógica, neste artigo, é definida como a articulação entre o conhecimento específico e o conhecimento pedagógico que origina o conhecimento pedagógico do conteúdo por meio da prática social da docência. Assim, a formação pedagógica nas licenciaturas exige a articulação dos conhecimentos específicos da matéria que o professor irá ensinar e dos conhecimentos pedagógicos tendo como ponto de partida e de chegada a prática pedagógica. Shulman (2005) enfatiza essa perspectiva ao defender que a prática docente é um conhecimento prático chamado de conhecimento pedagógico do conteúdo que se constrói na prática pedagógica como uma elaboração própria de cada professor a partir de seus conhecimentos teóricos e práticos. Seguindo essa perspectiva, a formação pedagógica assume como base epistemológica a luta de classes e a experiência que Martins (1996) propõe como forma de romper o eixo transmissão-assimilação que se estabelece na teoria como guia da prática. Assim, "[...] dá-se ênfase ao que o outro sabe, na prática social dos envolvidos, chegando-se ao nível da alteração das relações sociais” (MARTINS, 1996, p. 87). Nesta concepção a teoria se torna expressão da ação dos sujeitos, desde que ocorra um processo de reflexão, sistematização e análise desta ação.

Diante das contradições e tendências apresentadas para a formação de professores, são apreendidos que os desafios das licenciaturas no Brasil são imensos, porém, quando se trata das Licenciaturas em Física, os desafios tornam-se ainda maiores. Esses cursos enfrentam problemas de evasão, vagas ociosas e a consequente falta de professores com formação específica atuando no ensino médio. Apesar de as políticas públicas mostrarem-se eficientes no aumento de oferta de cursos e vagas, têm sido insuficientes para resolver o problema de falta de professores na educação básica, sendo preciso, urgentemente, aliar as políticas de aumento da oferta de cursos e vagas com políticas voltadas à melhoria da carreira docente.

\section{A ORGANIZAC̣ÃO CURRICULAR E A FORMAC̣ÃO PEDAGÓGICA NO CURSO DE LICENCIATURA EMM FÍSICA}

A articulação dos conhecimentos específicos e pedagógicos no curso de Licenciatura em Física foi constatada na análise do Projeto Pedagógico de Curso e nas práticas pedagógicas descritas pelos professores, em seus depoimentos durante as entrevistas. Para apresentar essa articulação foram organizados quatro subitens para auxiliar a compreensão do leitor. O primeiro focaliza as articulações da estrutura curricular proposta no Projeto Pedagógico de Curso. Em seguida são discutidas as estratégias de interdisciplinaridade desenvolvidas na Licenciatura em Física, depois o papel da pesquisa como metodologia na Licenciatura em Física e por fim o quarto subitem apresenta descrições das práticas pedagógicas desenvolvidas pelos professores do curso analisado.

\subsection{A ORGANIZAC̣ÃO CURRICULAR DA LICENCIATURA EM FÍSICA E AS ARTICULAC̣ÕES DE CONHECIMENTOS}

$\mathrm{Na}$ análise do Projeto Pedagógico de Curso, o exame realizado permite apontar a existência de três núcleos de disciplinas integrativas, para constituírem possíveis relações entre os saberes específicos e pedagógicos, chamados núcleo básico, núcleo específico e núcleo complementar (INSTITUTO, 2014). O básico 
tem como objetivo construir com o professor o embasamento teórico necessário para atuação e apresenta disciplinas de distintas áreas do conhecimento, de modo que são propostas quatro disciplinas de matemática, quatro estágios obrigatórios, além de outras diversas, em sua maior parte complementares à formação do professor. Já o núcleo específico tem como sua principal função estruturar o "[...] desenvolvimento de competências para a docência em Física” (INSTITUTO, 2014, p. 29); as disciplinas que o compõem têm em seus saberes conhecimentos da física. Assim, as disciplinas de conhecimento pedagógico geral são consideradas no núcleo básico, enquanto as pedagógicas que envolvem o ensino de física ou ciências estão no núcleo específico. Ainda nesse núcleo, foi registrada a presença de duas disciplinas de epistemologia e uma disciplina de cálculo. Por fim, no núcleo complementar, que tem o objetivo de ampliar a formação do licenciando em Física, foram identificadas três disciplinas, das quais se destacam Princípios da Ciência I e II, que propõem abordagens interdisciplinares para o ensino de ciências.

Quadro 2. Disciplinas do PPC Conforme Núcleos de Conhecimento

\begin{tabular}{|c|c|c|}
\hline NÚCLEO BÁSICO & NÚCLEO ESPECÍFICO & $\begin{array}{c}\text { NÚCLEO } \\
\text { COMPLEMENTAR }\end{array}$ \\
\hline $\begin{array}{l}\text { Álgebra } \\
\text { Cálculo I } \\
\text { Cálculo II } \\
\text { Cultura e Sociedade } \\
\text { Desenvolvimento Humano } \\
\text { e Aprendizagem } \\
\text { Didática } \\
\text { Estágio I } \\
\text { Estágio II } \\
\text { Estágio III } \\
\text { Estágio IV } \\
\text { Filosofia e Educação } \\
\text { Fundamentos Matemática } \\
\text { Gestão e Organização Escolar } \\
\text { Gestão e Políticas Públicas } \\
\text { História da Educação } \\
\text { Libras } \\
\text { Linguagem Acadêmico-Científica } \\
\text { Pesquisa e Docência } \\
\text { Prática Científica em Educação I } \\
\text { Prática Científica em Educação II } \\
\text { Sociologia da Educação } \\
\text { Tecnologias de Informação e } \\
\text { Comunicação } \\
\text { Trabalho de Conclusão de Curso I } \\
\text { Trabalho de Conclusão de Curso II }\end{array}$ & $\begin{array}{l}\text { Astronomia } \\
\text { Cálculo Vetorial Aplicado } \\
\text { Didática das Ciências } \\
\text { Eletromagnetismo } \\
\text { Epistemologia e História da Física } \\
\text { Epistemologia e História da Ciência } \\
\text { Equações Diferenciais Aplicada } \\
\text { Física Instrumental } \\
\text { Gravitação e Termodinâmica } \\
\text { Mecânica Geral } \\
\text { Metodologia do Ensino De Física } \\
\text { Métodos Computacionais para o } \\
\text { Ensino De Física } \\
\text { Ótica e Física Moderna } \\
\text { Projetos de Gravitação e } \\
\text { Termodinâmica } \\
\text { Projetos de Astronomia } \\
\text { Projetos de Eletromagnetismo } \\
\text { Projetos de Mecânica Geral } \\
\text { Projetos de Ótica e Física Moderna } \\
\text { Tópicos de Física Contemporânea }\end{array}$ & $\begin{array}{l}\text { Princípios das } \\
\text { Ciências I } \\
\text { Princípios das } \\
\text { Ciências II } \\
\text { Disciplina Optativa }\end{array}$ \\
\hline
\end{tabular}


Com o objetivo de promover a interdisciplinaridade e a articulação com a pesquisa, o Projeto Pedagógico de Curso propõe núcleos problematizadores transversais em cada fase do curso, que não são considerados disciplinas no curso de Licenciatura em Física, mas um instrumento de integração que inter-relaciona todas as disciplinas de cada fase do curso no desenvolvimento de uma pesquisa. Nesse sentido, eles assumem o papel de articulador de conhecimentos, da teoria e da prática pedagógica. Essa função articuladora está definida no trecho a seguir:

Essa proposta de matriz curricular integrativa - organizada pelo eixo condutor e eixo de formação, com núcleos problematizadores que propiciam ações e reflexões transversais, aliadas aos percursos horizontais e verticais que compõem a proposta curricular - visa superar a fragmentação e as lacunas que na maioria das vezes são criadas nos cursos de licenciatura, estruturados numa concepção tradicional de ciência. Visa superar também a dicotomia entre os saberes da ciência e os saberes pedagógicos, além do isolamento das unidades curriculares organizadas de forma disciplinar. Nesse sentido, busca-se formar um profissional capaz de integrar conteúdos específicos das ciências com o fazer pedagógico, tão necessários para um educador (INSTITUTO, 2014, p. 25).

Os temas dos núcleos problematizadores são: ciência e pesquisa; sujeito e sociedade; educação e escola; sujeito e aprendizagem; escola e ensino de ciências; educação em novos contextos; ação docente nas diversidades; e professor pesquisador, cujos objetivos são a problematização do existente, a possibilidade de transformação e a intervenção na realidade sociopedagógica. São ações sugeridas pelo Projeto Pedagógico de Curso para serem desenvolvidas nos núcleos problematizadores:

[...] intervenção pedagógica; experimento; análise de texto, artigo ou material acadêmico; produção de artigo; estudo dirigido; visita a espaços diversificados de educação formal e não-formal; saídas a campo; entrevistas, entre outras (INSTITUTO, 2014, p. 25).

Assim, destaca-se que, em sua organização curricular, o Projeto Pedagógico de Curso de Licenciatura em Física está proposto de modo que o licenciando tenha uma formação pedagógica articulada. Não há uma delimitação na organização curricular que favoreça primeiramente o conhecimento específico, para, em seguida, desenvolver os conhecimentos pedagógicos; ambos estão articulados na organização curricular. Isso pode, portanto, indicar uma licenciatura que se organiza em um modelo diferente do 3+1, como descrito por Gatti (2010) e Saviani (2009). É possível inferir, também, que esse curso segue as diretrizes para a formação de professores, construindo a formação de um educador em física, como apontado por Camargo (2007).

Reforçando as articulações desenvolvidas na Licenciatura em Física, nas entrevistas, os professores A e B realizaram uma comparação da licenciatura que cursaram com a licenciatura em que atuam como docentes, apontando suas diferenças e enfatizando o caráter de licenciatura que a Licenciatura em Física estabelece no Projeto Pedagógico de Curso e nas suas práticas. 


\begin{abstract}
física. Tanto que eu sempre converso com os nossos alunos aqui que eles têm uma bagagem na área pedagógica e na área de ensino muito maior do que a formação que a gente teve [...] (Professor A).

O que eu noto é que a licenciatura aqui ela está bastante voltada para o ensino. Têm várias disciplinas [...] que oportunizam que os alunos desenvolvam essas habilidades didáticas já desde o início. É uma coisa que eu pouco experimentei na minha formação [...] (Professor B).
\end{abstract}

\title{
3.2. AS ESTRATÉGIAS INTERDISCIPLINARES DA LICENCIATURA EM FÍSICA
}

Os núcleos problematizadores, como já apresentado, desenvolvem as diversas relações, promovendo a articulação da instituição com a educação básica pela pesquisa e entre os conhecimentos específicos e pedagógicos. As unidades curriculares Princípios da Ciência I e II desenvolvem a articulação de conhecimentos por meio de estratégias de prática como componente curricular. As disciplinas Projetos de Gravitação e Termodinâmica, Projetos de Astronomia, Projetos de Eletromagnetismo, Projetos de Mecânica Geral, Projetos de Ótica e Física Moderna também são consideradas articuladoras, pois, da mesma forma que Princípios da Ciência I e II, estabelecem formas de desenvolver os conteúdos de física por intermédio de experimentos, realizando ao mesmo tempo, com o licenciando, estratégias de ensino que articulam os conhecimentos de física e os conhecimentos pedagógicos.

No Projeto Pedagógico de Curso de Licenciatura em Física estão indicadas estratégias interdisciplinares e, consequentemente, o diálogo entre os conhecimentos desenvolvidos no curso, sendo ela defendida como um princípio integrador do currículo por dois caminhos:

\footnotetext{
O primeiro como exercício de compreensão da ciência enquanto forma de organização do mundo feita pela humanidade, a fim de ser comunicada. E o segundo como perspectiva pedagógica que permite organizar o ensino de modo que os conhecimentos das diferentes áreas sejam integrados para a compreensão dos fenômenos, sob diferentes pontos de vista. Nesse sentido, a interdisciplinaridade tem uma função instrumental, ou seja, trata-se de recorrer a um saber útil e utilizável para responder às questões e aos problemas sociais contemporâneos (INSTITUTO, 2014, p. 19).
}

Destacam-se, nas ações interdisciplinares, além dos núcleos problematizadores, as unidades curriculares Princípios da Ciência I e II, em que são desenvolvidos conteúdos de ciências pelos quais é possível relacionar três áreas do conhecimento (química, física e biologia) no desenvolvimento de práticas pedagógicas que articulam os conhecimentos específico e pedagógico. Essa articulação está expressa nas competências a ser desenvolvidas, especialmente em Princípios da Ciência I. Nessa unidade curricular, ${ }^{1}$ foi verificada a tentativa de interligar os conhecimentos científicos e tecnológicos de forma contextualizada, visando a uma prática pedagógica contextualizada e crítica. Desse modo, a unidade curricular contribui para que o licenciando potencialize sua formação, compreendendo que o fazer pedagógico, chamado por Shulman (2005) de conhecimento pedagógico do conteúdo, é construído na articulação entre teoria e prática e conhecimentos específicos e pedagógicos. 


\title{
São competências de Princípios da Ciência I:
}

\begin{abstract}
Compreender o mundo no qual a ciência é parte integrante, e construir referenciais teóricos que permitam uma prática pedagógica crítica e vinculados à realidade das escolas e da sociedade.

Compreender o conhecimento científico e tecnológico como resultados de uma construção humana, inseridos em um processo histórico-social.
\end{abstract}

Ler, articular e interpretar símbolos e códigos em diferentes linguagens e representações: sentenças, equações, esquemas, diagramas, tabelas, gráficos e representações geométricas (INSTITUTO, 2014, p. 42).

Assim, a interdisciplinaridade, na Licenciatura em Física, assume o conceito proposto por Santomé (1998) e promove a intercomunicação e interação entre conhecimentos de diferentes disciplinas. Sendo ela promovida pelas unidades curriculares Princípios da Ciência I e II e pelos núcleos problematizadores, com temas que articulam as disciplinas, mantendo a organização curricular com disciplinas definidas, reforça-se que o currículo dessa licenciatura se apresenta de forma colaborativa, como propõe Marcelo (1999).

Nesse contexto, a relação da instituição formadora com as escolas da educação básica torna-se fundamental para garantir uma formação contextualizada com a realidade social em que a instituição está inserida e as escolas nas quais o licenciado irá atuar. No Projeto Pedagógico de Curso de Licenciatura em Física, essa relação é evidenciada em dois trechos e a forma como ela será realizada fica explícita na descrição das atividades dos núcleos problematizadores:

A própria estrutura curricular favorecerá a articulação entre estes campos uma vez que serão possibilitadas ao longo de todo o curso as aproximações com espaços reais de trabalho. Nas escolas das redes públicas e em espaços não formais de ensino, serão realizadas aproximações ou atividades sistematizadas de pesquisa e extensão em articulação direta com as atividades de ensino previstas na matriz curricular.

$[\cdots]$

Como a docência é o foco do curso - o eixo condutor - serão realizadas aproximações sistemáticas e contínuas com as redes públicas voltadas à educação básica e à educação profissional de nível médio. O aluno deverá ter oportunidade de conhecer e vivenciar esses espaços em diferentes etapas de sua formação, de maneira que esta não ocorra exclusivamente no momento de desenvolvimento de seu estágio curricular supervisionado (INSTITUTO, 2014, p. 26-27).

$\mathrm{O}$ professor $\mathrm{C}$ destacou, durante a entrevista, as discussões que o grupo de professores do curso tem realizado para concretizar essa relação da instituição com a educação básica pela pesquisa, por meio dos núcleos problematizadores, mas indicou que essa relação está em construção. Já o professor A destacou suas práticas interdisciplinares nas unidades curriculares de PCI I:

Quem vai para o PIBID ${ }^{2}$ consegue ir e executar com o aluno real, mas se não eles estão muito aqui, na prática, na experimentação. Essa é uma reflexão que a gente começou a fazerer na última 
reunião e de repente tražer grupos para cá grupos de alunos de escolas para mostrar para eles o Núcleo Problematizador. Ele pode vir muito mais forte até para garantir o vinculo das PPCCs ${ }^{3}$ com a escola. Quando a gente montou o Núcleo Problematizador a ideia era essa ir lá à escola e executar lá, mas isso a gente precisa enquanto docente da licenciatura se desamarrar desse receio de ir para escola ou desse conforto talvez de não ir para a escola. (Professor C)

Para que o aluno no Ensino Médio perceba que a química a física e a biologia não estão em uma caixinha. Se o professor de biologia apresentasse um problema como esse não ia ter escapatória ele teria que correr atrás da física a quimica para solucionar o problema. Então é um trabalho que realmente é interdisciplinar porque não tem como fugir. Eu vou me deparar das outras disciplinas e vou ter que correr atrás. Um exemplo é da parte de mecânica. Eles desenvolveram carrinhos que eram movidos por diversas fontes de energia, mas o foco é como ele pensando como professor em como ele vai utilizar aquilo no Ensino Médio. Da mesma forma eles têm os conteúdos apresentados e a gente procura fazer essa ponte com o Ensino Médio então essa transposição didática nesse caso ela ficou mais voltada para desenvolvimento de alguma coisa que tenha que construir realmente (Professor A).

Dessa forma, é provável que a interdisciplinaridade, no Projeto Pedagógico de Curso de Licenciatura em Física, não se apresenta de forma integrada, pois há limites disciplinares definidos nas disciplinas dispostas na matriz curricular conforme o quadro 2. Entretanto, é possível afirmar que é um currículo colaborativo, pois as disciplinas de cada fase estão interligadas pelas temáticas dos núcleos problematizadores. Desse modo, a Licenciatura em Física estabelece um currículo colaborativo (MARCELO, 1999). Além disso, o documento mantém a estrutura disciplinar, mas busca inter-relações entre os conhecimentos, tendo a pesquisa um papel metodológico na organização curricular.

$\mathrm{Na}$ proposta de curso da Licenciatura em Física, a interdisciplinaridade é colocada como um princípio integrador dos conhecimentos, o que aponta que a formação do professor não pode ser realizada sem que os diferentes conhecimentos da docência se relacionem. Nesse sentido, as unidades curriculares Princípios da Ciência I e II possibilitam que a formação pedagógica seja coerente com as inovações pedagógicas da racionalidade prática. Em suas falas, nas entrevistas, os professores indicam essas potencialidades e mesmo suas dificuldades práticas de desenvolver uma unidade curricular interdisciplinar. O estudo permite ressalvar que as práticas interdisciplinares da Licenciatura em Física favorecem a intercomunicação e a interação das disciplinas. Isso se expressa, especialmente, em Princípios da Ciência I e II, em que as práticas pedagógicas dos professores revelam a articulação de conhecimentos, para que o licenciando compreenda as relações da física com outras áreas do conhecimento, além de privilegiar que o discente pense nas atividades como professor de física.

\subsection{O PAPEL DA PESQUISA NA ORGANIZAĈ̣̃O CURRICULAR DA LICENCIATURA EM FÍSICA}

A pesquisa, no Projeto Pedagógico de Curso, assume um papel didático, à medida que será instrumento de aprendizagem do licenciando, possibilitando o conhecimento de metodologia científica necessário para o desenvolvimento 
de pesquisa e, concomitantemente, sendo uma possibilidade de aproximação da instituição com a educação básica.

Ela tem importância significativa na formação pedagógica do professor; na Licenciatura em Física, é uma prática metodológica, explicitada nas práticas dos professores, e se apresenta como uma forma de relacionar e construir conhecimentos. Lüdke (2009), ao relatar suas investigações sobre a pesquisa realizada pelos professores da educação básica no Brasil, ressalta, a partir das falas deles, a disposição para a pesquisa daqueles que têm formação em mestrado e/ou doutorado, como também a falta de formação para a pesquisa em sua formação inicial na graduação e até a ausência da metodologia científica em seus cursos de licenciatura.

No Projeto Pedagógico de Curso de Licenciatura em Física, a metodologia de pesquisa tem espaço em diversas disciplinas, como Linguagem AcadêmicoCientífica, Pesquisa e Docência, Prática Científica em Educação I, Prática Científica em Educação II, Trabalho de Conclusão de Curso I, Trabalho de Conclusão de Curso II, Princípios da Ciência I e Princípios da Ciência II.

[...] o eixo condutor do curso conceberá o professor como sujeito de reflexão e pesquisa e o eixo de formação terá a pesquisa como princípio educativo.

A pesquisa, neste caso, constitui-se instrumento de ensino e conteúdo de aprendizagem, especialmente para propiciar a análise dos contextos em que se inserem as situações cotidianas da docência, para a construção de conhecimentos que ela demanda e para a compreensão dos demais processos implicados na tarefa de educar. Ela possibilita que o professor em formação aprenda a conhecer a realidade na sua complexidade, de modo que possa agir considerando os múltiplos intervenientes relativos aos processos de aprendizagem, à vida dos alunos e ao contexto sociocultural em que está inserida a escola. (INSTITUTO, 2014, p. 19).

Enfatiza-se que a Licenciatura em Física apresenta um diferencial diante desse cenário e desenvolve a pesquisa e a metodologia científica em diversas disciplinas ao longo do curso. Essas disciplinas totalizam 640 horas de carga horária (Tabela 1) e representam aproximadamente $20 \%$ da carga horária total do curso. Na primeira fase da licenciatura, duas disciplinas desenvolvem conteúdos relacionados à metodologia científica: Linguagem Acadêmico-Científica e Pesquisa e Docência. Em Linguagem Acadêmico-Científica, são desenvolvidas estratégias de escrita e formatação de trabalhos acadêmicos e, em Pesquisa e Docência, os tipos de pesquisa na educação e a pesquisa em sala de aula. Na segunda fase do curso, as disciplinas Prática Científica em Educação I e Princípios da Ciência I têm o objetivo de desenvolver a metodologia científica, mas de formas distintas: em Prática Científica em Educação I, é elaborado um projeto de pesquisa com enfoque na reflexão sobre o contexto escolar e, em Princípios da Ciência I, a pesquisa é utilizada como metodologia de ensino, como articuladora de conhecimentos específicos e pedagógicos. $\mathrm{Na}$ terceira fase, encontram-se as disciplinas Prática Científica em Educação II e Princípios da Ciência II; em Prática Científica em Educação II, é realizada a coleta de dados e o artigo final da pesquisa. Por fim, na sétima fase do curso, é feito o Trabalho de Conclusão de Curso I e, na oitava fase, Trabalho de Conclusão de Curso II. Em 
Trabalho de Conclusão de Curso I, o licenciando apresenta o projeto da pesquisa, enquanto em Trabalho de Conclusão de Curso II, é realizada a coleta de dados, a escrita da pesquisa e a defesa em banca examinadora.

Tabela 1. Distribuição da carga horária do Projeto Pedagógico de Curso: pesquisa

\begin{tabular}{lcc}
\multicolumn{1}{c}{ Área do conhecimento } & Fase & Carga horária (h) \\
\hline Linguagem Acadêmico-Científica & 1 & 80 \\
Pesquisa e Docência & 1 & 40 \\
Prática Científica em Educação I & 2 & 40 \\
Prática Científica em Educação II & 3 & 40 \\
Princípios da Ciência I & 2 & 160 \\
Princípios da Ciência II & 3 & 160 \\
Trabalho de Conclusão de Curso I & 7 & 40 \\
Trabalho de Conclusão de Curso II & 8 & 640 \\
\hline Total & & 60 \\
\hline
\end{tabular}

Fonte: Adaptado de Instituto (2014).

O foco na pesquisa desde a primeira fase do curso possibilita que os estágios obrigatórios presentes a partir da quinta fase desenvolvam a pesquisa sobre a prática, conforme relatado pelo professor C:

Acho que tem uma questão legal da pesquisa como princípio educativo. Mas não é uma pesquisa para

ser acadêmica é uma pesquisa que faça pensar sobre a prática. Em PCE ele acaba faz̧endo isso e os estágios eles fazem isso. Então eles vão pesquisar uma metodologia ou o processo de aprendizagem. [...] O resultado final para aprovação é o artigo da pesquisa. Eles vão ter toda uma sequência didática em execução em sala de aula que vão coletar dados para pesquisa. São duas frentes: um é a intervenção pedagógica e outra é o projeto. Que vai estar atrelado a sequência didática e via sequência didática ele vai coletar dados para depois fazer o artigo. Isso consegue atrelar a prática pedagógica $e$ análise do meu fazer enquanto docente no espaço real. Isso forma o professor reflexivo o professor pesquisador. A pesquisa não é só acadêmica ela está no dia a dia.

Dessa forma, percebe-se que a Licenciatura em Física assume a pesquisa como princípio educativo, que na proposição de Lüdke (2009) é basilar na formação docente considerando a pesquisa como proposta metodológica para o ensino, articulando conhecimentos, estabelecendo a aproximação da Educação Básica e compreendendo o licenciando, professor em formação, como produtor 
de conhecimentos.

\subsection{AS PRÁTICAS PEDAGÓGICAS DESENVOLVIDAS PELOS PROFESSORES DA LICENCIATURA EM FÍSICA}

$\mathrm{Na}$ entrevista com o professor C, seu relato aponta para compreender o destaque dado à escola nas disciplinas pedagógicas. Nas descrições de práticas desse professor na disciplina Gestão e Políticas Públicas, está salientada a relação com a escola. Destaca-se ainda, nas práticas citadas por ele, a interlocução de conhecimentos realizada entre as disciplinas Desenvolvimento Humano e Didática, para a aprendizagem da didática e do planejamento do ensino, como preconizado por Santomé (1998). Essa relação pode favorecer o entendimento do ensino e da aprendizagem como um processo integrado que tem como objetivo o desenvolvimento do sujeito como um todo.

Em GPP sim, eles iam para escola. Eles tinham que escolher uma politica pública que tinham estudado e eles tinham que ir à escola perceber como essa política pública acontece. Então a gente entende que pode refletir sobre a prática, traz̧endo o espaço da escola ou a ação educativa como uma forma de vivenciar on ao menos observar lá espaço educativo para depois vir e fažer aqui (Professor C).

Este professor destaca ainda, a interlocução de conhecimentos realizada entre as disciplinas Desenvolvimento Humano e Aprendizagem para a aprendizagem do planejamento do ensino em Didática e Currículo. Essa relação pode favorecer o entendimento do ensino e da aprendizagem como um processo integrado entre disciplinas.

Em Didática e Currículo do curso novo, Desenvolvimento Humano e Aprendizagem, eles têm que construir uma sequência didática que é o que a gente conta como PPCC. Eles estão aprendendo em didática o modelo de uma sequência didática e eles estão aprendendo em Desenvolvimento Humano e Aprendizagem como o sujeito aprende, as teorias de aprendizagem que eles vão colocar elas lá nas teorias de ensino então eles organizam uma sequência didática de física. O conteúdo de física é sempre bem deficitário porque ele ainda não tem um bom domínio e isso não tem implicações na avaliação (Professor C).

Além disso, no relato das práticas do professor A, há indicação de atividades que evidenciam a preocupação com a formação pedagógica em uma disciplina que desenvolve conhecimentos específicos da física buscando a articulação de conhecimentos realizada na prática pedagógica dos professores.

Por exemplo, agora eu estou dando uma disciplina nova para mim que é FXX, Física do século XX [...] Então nessa unidade curricular [...] a gente apresenta o conteído, os conceitos da física moderna e tenta mostrar para eles como eles podem trabalhar isso em sala de aula. Então um primeiro passo a gente vai ver como esse conteúdo que a gente está trabalhando está apresentado no livro didático de Ensino Médio. Então a gente traz vários autores ali de Ensino Médio e vai fazer uma análise. Olha, en já expliquei relatividade para eles, eles já conhecem o conteúdo agora eles têm capacidade de olhar para o livro e ver se está contemplado ou não esse conteúdo. Esse é um primeiro passo: eles vão 
analisar os livros [...] vão relatar se em cada um deles está contemplado ou não está e se da forma que está ali é adequada ou não. Dai gera uma discussão sobre isso. Depois num segundo momento eles vão ter que preparar uma sequência didática ou um plano de aula e vão ter que executar em sala entre eles como se fosse uma aula para Ensino Médio (Professor A).

O professor B descreveu, na entrevista, as atividades que desenvolve em sala de aula. Em seu relato, nota-se a preocupação em ensinar de forma significativa e contextualizada, instigando os estudantes a refletir sobre as questões ambientais e pensar o tema em uma perspectiva pedagógica.

Então a gente tem feito, no semestre passado, trabalhar com metodologias de painel, de seminário, de análise de projetos em educação ambiental. A partir desses estudos que os alunos fazem de temas como processos antrópicos e impactos ambientais, história da educação ambiental, dos tratados internacionais, como os países discutem o tema, o surgimento da educação ambiental formal, eles discutem isso fazendo leituras, eles selecionam textos escrevem um texto apresentam então na forma de seminário, painel e discutem e depois a gente tem bastante debate. As turmas também favorecem isso. Eles são muito dinâmicos, eles gostam do debate da discussão então as aulas caminham nesse sentido. Ou então eu seleciono um texto, eles leem e a gente discute também. [...] Por fim também tento priorizar uma saída de campo (Professor B).

Conforme afirmado por Candau (1999), a didática se constitui e se altera com as relações entre os diferentes conhecimentos, estruturando-se, dessa forma, pela articulação com a área específica de formação do licenciado. Essa concepção pode ser visualizada na organização curricular do curso de Licenciatura em Física nas práticas pedagógicas que os professores entrevistados descreveram. As diferentes áreas específicas (física, biologia e pedagogia, por exemplo) assumem novas epistemologias e formas ao se articularem para promover a formação pedagógica. Igualmente Lüdke e Cruz (2005) afirmam a importância desta articulação entre conhecimentos específicos e conhecimentos pedagógicas e Prática escolar.

O professor B também relatou na entrevista as atividades que desenvolve nas unidades curriculares Princípios da Ciência I e II. Nos trechos a seguir, percebe-se a dificuldade de desenvolver a interdisciplinaridade, pois é necessário relacionar três disciplinas, havendo três professores para promovê-la. O professor B salientou o apego e a hierarquia colocada por alguns professores como um obstáculo para a integração efetiva da unidade curricular. Apesar disso, nas práticas descritas, evidencia-se mais.

Uma vez a preocupação em ensinar de forma significativa e contextualizada, instigando os estudantes a refletir mediante estratégias pedagógicas em que o licenciando está inserido de forma ativa no seu processo de ensino-aprendizagem, ao mesmo tempo em que articula os conhecimentos específicos e pedagógicos ao elaborar situações de aprendizagem.

Em PCI II a gente trabalhou com temas que tinham relação com a física, a química e a biologia. A gente foca um ponco mais em combustiveis fósseis e energias renováveis. Então a gente trabalhou sobre petróleo. Os alunos, por exemplo, assistiam a um video, um documentário sobre o pré-sal. A partir do documentário sobre o pré-sal os alunos foram buscar dados mais 
atuais sobre o pré-sal. É depois disso a gente comecou a trabalhar... Por exemplo, em Biologia eu trabalhei as questões relacionadas... Os problemas ambientais relacionados aos combustiveis fosseis. A gente discutiu a formação dos fósseis e um pouco de geologia. Seres vivos. E na química o professor trabalhou química orgânica e na física o professor trabalhou com formas de energia e tal. Depois a gente caminhou para a energia renováveis sempre na forma de PPCC, sempre enfatizando isso, eles desenvolveram aulas. (Professor B).

As práticas pedagógicas desenvolvidas pelos professores do curso de Licenciatura em Física demonstram a preocupação com a prática profissional do licenciando, buscando auxiliá-lo a refletir e compreender a prática pedagógica e a inter-relação dos conhecimentos. Além disso, os professores demonstram que, em um curso de licenciatura, o conhecimento pedagógico é fundamental e pode ser trabalhado por todos os professores, inclusive nas disciplinas consideradas específicas, conforme Gatti (2010) tem ponderado como essencial nos cursos de formação de professores. Nas análises, foi constatado que a Licenciatura em Física não privilegia conhecimento específico, em detrimento do conhecimento pedagógico, ou seja, a proposta se mostra um movimento na trajetória de uma formação articulada, rumo a uma licenciatura para a formação do Educador em Física. O curso apresenta formas de interlocução entre conhecimentos e busca contextualizar a educação e a ciência na história e na sociedade.

\section{CONSIDERACְÕES FINAIS}

A partir da nova reformulação dos cursos de licenciatura (Resoluções CNE n ${ }^{\circ} 1 / 2002, n^{\circ} 2 / 2002$ e no 2/2015) das demandas da educação básica, a organização curricular das licenciaturas exigiu a busca por alternativas em que a formação pedagógica se articulasse ao conhecimento específico, fomentando práticas pedagógicas contextualizadas e inovadoras, conforme discutido neste texto. Diante disso, este artigo estabeleceu como propósito identificar e analisar as prioridades apresentadas no Projeto Pedagógico de Curso para a formação de professores no curso de Licenciatura em Física e a partir da descrição das práticas pedagógicas dos professores apontar que articulações de conhecimentos são estabelecidas na formação dos licenciandos. Portanto, foi possível ir além do objetivo inicial, que propunha descrever as práticas. Desse ponto de vista, a análise permite indicar pontos desatacados nesse curso e que se mostram como potencialidades para a formação de professores.

A análise do Projeto Pedagógico de Curso evidencia que o curso busca, em sua organização do conhecimento, a articulação entre conhecimentos específicos e pedagógicos e favorece ao futuro professor a compreensão da relação entre esses conhecimentos, pois não basta saber o que ensinar, é fundamental compreender como ensinar. Nesta perspectiva a promoção de uma formação em colaboração entre professores de modo a realizar atividades de investigação nos núcleos problematizadores são tentativas da Licenciatura em Física romper com um modelo 3+1 das licenciaturas.

O princípio de vinculação entre teoria e prática e prática e teoria, mesmo que de modo singular, em algumas situações exemplares, tem sido encorajado por 
estar expresso na proposta do curso e constituir-se tema de discussão nas reuniões. Esse princípio está presente na prática docente ao assumir a pesquisa como princípio educativo investigando as disciplinas de conhecimentos específicos em conexão com as disciplinas pedagógicas, na busca de um curso coeso em que não há uma relação hierarquizada entre os conhecimentos. Essas práticas apontam para a inserção da pesquisa como processo didático, ainda que não ocorra no conjunto das disciplinas.

Além disso, são perceptíveis na organização curricular e na discussão dos professores a busca de aproximação com a escola básica, por meio de iniciativas de desenvolvimento de projetos de trabalho pelos estudantes, nas disciplinas dos núcleos problematizadores, para estabelecer contato com situações que envolvem o trabalho docente na educação básica. Essa busca de aproximação tem sido alvo de discussão entre os professores, nas reuniões do colegiado do curso e do Núcleo Docente Estruturante.

Ainda, a valorização da docência ocorre no curso, pois a inserção em produções de planos de aula e sequências didáticas evidenciam conceitos e conteúdos específicos abordados pedagogicamente. Nos relatos dos professores do curso de Licenciatura em Física foi indicado que a metodologia de abordagem das disciplinas se direciona para a superação de modelos centrados na transmissão de conteúdos. Assim, se expressa um esforço para desenvolver um curso coerente entre o que é proposto e o que é realizado.

Contudo, há pontos nas análises feitas, tanto do Projeto Pedagógico de Curso, como nas práticas relatadas, que expressam questões para novas discussões, por exemplo, os núcleos problematizadores ainda não consolidados na Licenciatura em Física, pois estão buscando o estabelecimento de práticas interdisciplinares para a articulação de conhecimentos. Além disso, a aproximação com a educação básica é colocada em movimento, tanto na aproximação do espaço da escola como durante o tempo da realização nas disciplinas e nas práticas, na tentativa de conquista dessas articulações em totalidade. Esse aspecto, embora já assumido por parte dos docentes, precisa ser ampliado no conjunto das disciplinas, porque quando realizado, nem sempre se relaciona à educação básica, conservando um caráter de pesquisa geral e encaminhado aos conhecimentos de Física. Apesar disso, o curso tem buscado alternativas para desenvolver as atividades que articulem os diversos campos do conhecimento.

As dificuldades para a sua concretização apontadas pelos professores estão mais direcionados aos aspectos de operacionalização e de gestão, tais como excesso de reuniões e atividades administrativas, restringindo os momentos de discussão e construção coletiva das práticas. Entretanto, é essencial valorar que os órgãos de gestão e os professores investem e priorizam formar um "Educador em Física". A investigação realizada permitiu constatar que, desde a primeira até a última fase do curso, há um esforço para que os licenciandos desenvolvam um processo de formação na direção de se tornarem professores. Com efeito, o curso examinado expressa avanços no campo da formação de professores ao se constituir como um curso de Licenciatura em Física que articula os conhecimentos específicos e pedagógicos. 


\section{REFERÊNCIAS}

ARAÚJO, R. S.; VIANNA, D. M. A história da legislação dos cursos de Licenciatura em Física no Brasil: do colonial presencial ao digital a distância. Revista Brasileira de Ensino de Física, São Paulo, v. 32, n. 4, out./dez. 2010.

BARDIN, L. Análise de conteúdo. Porto: 70, 1999.

BRASIL. Decreto-Lei 1190 de 04 de abril de 1939. Da organização à Faculdade nacional de Filosofia. Rio de Janeiro, 1939. Disponível em: < http://www.planalto.gov.br/ccivil_03/decretolei/1937-1946/Del1190.htm>. Acesso em: 13 ago. 2017.

BRASIL. Parecer Conselho Nacional de Educação 1.304, de 04 de dezembro de 2001. Diretrizes Nacionais Curriculares para Física. Brasília, 2001. Disponível em: < http://portal.mec. gov.br/cne/arquivos/pdf/CES1304.pdf.>. Acesso em: 26 mai. 2016.

BRASIL. Resolução Conselho Nacional de Educação 02 de 19 de fevereiro de 2002. Institui a duração e a carga horária dos cursos de licenciatura, de graduação plena, de formação de professores da Educação Básica em nível superior. Brasília, 2002b. Disponível em: <http://portal.mec.gov.br/ cne/arquivos/pdf/CP022002.pdf>. Acesso em: Acesso em: 26 mai. 2016.

BRASIL. Lei 11. 892, de 29 de dezembro de 2008. Institui a rede federal de educação profissional, científica e tecnológica. Brasília, 2008. Disponível em: < http://www.planalto.gov.br/ccivil_03/_ ato2007-2010/2008/lei/111892.htm>. Acesso em: 26 mai. 2016.

BRASIL. Resolução $\mathbf{n}^{\circ} 02$ do Conselho Nacional de Educação de 01 de julho de 2015. Diretrizes nacionais para a formação de professores da Educação Básica. Brasília, 2015. Disponível em: <http:/ portal.mec.gov.br/index.phpoption $=$ com_docman\&view $=$ download\&alias $=17719$ res-cne-cp-002-03072015\&Itemid=30192>. Acesso em: 26 mai. 2016.

CANDAU, V. Rumo a uma nova didática. Petrópolis: Vozes, 1999.

CAMARGO, S. Discursos presentes em um processo de reestruturação curricular de um Curso de Licenciatura em Física: o legal, o real e o possível. 2007. Tese (Doutorado em Doutorado em Educação para a Ciência) - Faculdade de Ciências, UNESP, Bauru, 2007.

DOURADO, L. F. Diretrizes curriculares nacionais para a formação inicial e continuada dos profissionais do magistério da educação básica: concepções e desafios. Educação e Sociedade, Campinas, v. 36, nº. 131, p. 299-324, abr.-jun., 2015. <Disponível em: http://www.scielo.br/pdf/es/ v36n131/1678-4626-es-36-131-00299.pdf.> Acesso em: 15 abr. 2018.

FLICK, U. Introdução à pesquisa qualitativa. Porto Alegre: Artmed, 2009.

GATTI, B. A. Formação de professores no Brasil: características e problemas. Educação e Sociedade, Campinas, v. 31, n. 113, p. 1355-1379, out./dez. 2010.

GATTI, B. A.; BARRETO, E. S. S. Professores do Brasil: impasses e desafios. Brasilia: UNESCO, 2009.

HIGA, I.; GARCIA, N. M. D. Formação de professores de Física: problematizando ações governamentais. Educação: Teoria e Prática, v. 22, n. 40, maio/ago. 2012.

LÜDKE, M. (org.). O que conta como pesquisa? São Paulo: Cortez, 2009.

LÜDKE, M.; ANDRÉ, M. E. D. A. Pesquisa em educação: abordagens qualitativas. São Paulo: Pedagógica e Universitária, 1986. 
LÜDKE, M; CRUZ, G. B. Aproximando universidade e escola de educação básica pela pesquisa. Cadernos de Pesquisa, v. 35, n. 125, p. 81-109, mai./ago. 2005.

INSTITUTO FEDERAL DE EDUCAÇÃO, CIÊNCIA E TECNOLOGIA. Projeto pedagógico de curso do curso de Licenciatura em Física. Santa Catarina, 2014. Disponível em: <http:// cs.ifsc.edu.br/portal/files/LICENTIATURA_FÍSICA_JARAGUÁ.pdf>. Acesso em: 26 mai. 2016.

MARCELO, C. G. Formação de professores: para uma mudança educativa. Porto: Porto, 1999.

ROMANOWSKI, J. P. As licenciaturas no Brasil: um balanço de teses e dissertações dos anos 1990. 2002. Tese (Doutorado em Educação) - Faculdade de Educação, USP, São Paulo, 2002.

SANTOMÉ, J. T. Globalização e interdisciplinaridade: o currículo integrado. Porto Alegre: ARTMED, 1998.

SAVIANI, D. Formação de professores: aspectos históricos e teóricos no contexto brasileiro. Revista Brasileira de Educação, Rio de Janeiro, v. 14, n. 40, jan./abr. 2009.

SHULMAN, L. S. Conocimiento y enseñanza: fundamentos de la nueva reforma. Revista de Currículum y Formación del Profesorado, v. 9, n. 2, 2005.

TREVIÑOS, A. N. S. Introdução à pesquisa em ciências sociais: a pesquisa qualitativa em educação. São Paulo: Atlas, 1987.

\section{NOTAS}

${ }^{1}$ Utilizado o termo "unidade curricular" pela interdisciplinaridade desenvolvida, conforme Santomé (1998), que define o termo como inter-relação dos conhecimentos nos currículos.

${ }^{2}$ Sigla de Programa Institucional de Bolsas de Iniciação à Docência.

${ }^{3}$ Sigla de Práticas Pedagógicas como Componente Curricular.

${ }^{4}$ Sigla das disciplinas Prática Científica em Educação I e II.

${ }^{5}$ Sigla da disciplina Gestão e Políticas Públicas.

Submetido em 26/09/2017

Aprovado em 30/05/2018

\section{Contato:}

Pontifícia Universidade Católica do Paraná (PUC.PR)

Escola de Educação e Humanidades

Rua Imaculada Conceição, 1155 - Prado Velho

CEP: 80215-901 - Curitiba, PR - Brasil 